\title{
Accuracy of screening instruments in identifying central auditory processing disorders: an integrative literature review
}

\author{
Thalinny da Costa Silva ${ }^{1}$ \\ https://orcid.org/0000-0003-2737-1197 \\ Aryelly Dayane da Silva Nunes ${ }^{2}$ \\ https://orcid.org/0000-0002-3814-2675 \\ Thainá Ruth França de Farias ${ }^{3}$ \\ https://orcid.org/0000-0003-4715-1757 \\ Ana Beatriz Santos ${ }^{3}$ \\ https://orcid.org/0000-0002-8433-6729 \\ Karinna Veríssimo Meira Taveira ${ }^{4}$ \\ https://orcid.org/0000-0001-6978-4083 \\ Sheila Andreoli Balen ${ }^{5}$ \\ https://orcid.org/0000-0003-1353-4362
}

Universidade Federal do Rio Grande do Norte - UFRN, Hospital Universitário Onofre Lopes, Laboratório de Inovação Tecnológica em Saúde - LAIS, Programa Associado de Pós-Graduação em Fonoaudiologia, Natal, Rio Grande do Norte, Brasil.

Universidade Federal do Rio Grande do Norte - UFRN, Hospital Universitário Onofre Lopes, Laboratório de Inovação Tecnológica em Saúde - LAIS, Programa de Pós-Graduação em Saúde Coletiva, Natal, Rio Grande do Norte, Brasil.

Universidade Federal do Rio Grande do Norte - UFRN, Hospital Universitário Onofre Lopes, Laboratório de Inovação Tecnológica em Saúde - LAIS, Curso de Graduação em Fonoaudiologia, Natal, Rio Grande do Norte, Brasil.

Universidade Federal do Rio Grande do Norte - UFRN, Departamento de Morfologia, Programa Associado de Pós-Graduação em Fonoaudiologia, Natal, Rio Grande do Norte, Brasil.

Universidade Federal do Rio Grande do Norte - UFRN, Departamento de Fonoaudiologia, Programa Associado de Pós-Graduação em Fonoaudiologia, Natal, Rio Grande do Norte, Brasil.

Research support source: This study was financed in part by the Coordenação de Aperfeiçoamento de Pessoal de Nível Superior Brasil (CAPES) - Finance Code 001.

Conflict of interests: Nonexistent

\section{(c) (i)}

Received on: October 11, 2020

Accepted on: March 8, 2021

Corresponding address:

Sheila Andreoli Balen

Rua Desembargador Hemetério Fernandes,

1162, 102

Natal, RN, CEP: 59015-110, Brasil

E-mail: sheila@sheilabalen.com.br

\section{ABSTRACT}

Purpose: to assess the literature about the accuracy of screening instruments for identifying the Central Auditory Processing Disorders (CAPD).

Methods: search strategies were performed in the following databases: CINAHL, LILACS, PubMed /MEDLINE, Scopus, Speechbite and Web of Science. A search was also carried out in the grey literature. Four independent reviewers selected the included articles using a two-phase process based on the eligibility criteria. Two reviewers independently collected the required information from the included articles. The diagnostic methods were minimal batteries of behavioral tests to assess auditory processing skills.

Results: from 1,366 articles found on all databases, after analysis of title and abstract, 36 were selected for the next phase, when 5 articles were finally included. It was found that the studies included were related to five instruments applied in children. The specificity was higher than $70 \%$, but just the Mottier test and Screening Test for Auditory Processing (STAP), and Screening Checklist for Auditory Processing (SCAP) showed sensibility higher than $70 \%$.

Conclusion: Mottier was the most accurate CAPD screening test. There was no homogeneity in the presentation of the pass/fail criterion, or in the gold reference test used to establish the presence of CAPD.

Keywords: Children; Hearing; Mass Screening; Auditory Perceptual Disorders; Hearing Test 


\section{INTRODUCTION}

The Central Auditory Processing Disorder (CAPD) is defined by the difficulty in interpreting verbal and nonverbal auditory stimuli, resulting from the presence of auditory dysfunction of the central auditory nervous system (CANS) in its afferent pathways, with bottom-up modulation, and/or in the efferent pathways, which receive top-down modulation and involve language, speech, cognition, attention, memory and fluid reasoning ${ }^{1,2}$. The International Statistical Classification of Diseases and Related Health Problems (ICD-10) characterizes the Auditory Processing Disorder as an Impairment of Auditory Discrimination, under the classification "Other abnormal auditory perceptions" (H93.25) ${ }^{3}$.

Currently, there is an understanding that there is a correlation between CAPD and other developmental disorders in children, such as Autism Spectrum Disorder, Dyslexia and specific language impairment ${ }^{1}$. Thus, there are gaps in the literature regarding evidence of purely auditory deficit in children diagnosed with $\mathrm{CAPD}^{2}$, since this alteration can manifest itself as a co-occurrence of other disorders. These changes in the Central Auditory System can cause several damages to the development and learning process of children ${ }^{4}$, impacting the performance of personal activities and quality of life'.

In the literature, it is possible to categorize auditory processing screening instruments into various types, such as tests with recorded stimuli ${ }^{5}$, questionnaires and checklists $^{6}$, scales ${ }^{7}$, software ${ }^{8}$ and online program ${ }^{9}$ and tests with uncalibrated sounds ${ }^{10}$.

In the study by Volpatto et al. ${ }^{11}$, it is possible to see, through a systematic review, the questionnaires, and checklists most used in Brazil for auditory processing screening available in Portuguese. Among the translated and/or adapted tools, the Auditory Processing Domains Questionnaire (APDQ) is the only questionnaire that has been validated ${ }^{11}$. Another review that focused on analyzed studies that applied CAPD screening in schoolchildren did not use the eligibility criterion studies of comparing the CAPD screening with diagnosis procedures in CAPD including behavioral assessment battery tests ${ }^{12}$. This eligibility is necessary for measuring the accuracy of the CAPD screenings protocols. So, this gap in literature remains.

The broad spectrum of alterations inherent to the diagnosis and clinical implications of the CAPD makes it very important that the screening instruments have diagnostic validity for them to be apt to quickly and effectively detect this disorder. The more valid the screening of CAPD is, greater are the chances of the subject to be properly identified as with a high or low probability to have CAPD and be effectively referred for diagnostic evaluation when necessary.

Therefore, it is of great importance to screen, as early as possible, the central auditory processing disorders. It is important that the process of improving, or even developing methods of auditory screening be approached with caution ${ }^{13}$, as it is the moment when the professionals collect information on the subjects' health, education and well-being, which are important parameters for them to perform their daily tasks ${ }^{14}$. Based on the identification, the child can be adequately diagnosed and, afterwards, referred for intervention ${ }^{13}$.

In this way, this review aimed at studying what is referred to in the literature regarding the accuracy of screening instruments in identifying the CAPD.

\section{METHODS}

This integrative literature review was guided by the question: "What is the accuracy of the screening instruments in identifying the CAPD?". After the question had been developed in the first phase, the second phase of the integrative review was begun, involving the survey of the literature in six databases, namely, Cumulative Index to Nursing and Allied Health Literature (CINAHL), Literature in the Health Sciences in Latin America and the Caribbean (LILACS), PubMed (including MEDLINE), Scopus, SpeechBITE and Web of Science, in addition to two grey literature databases, Google Scholar and OpenGrey.

Mesh terms, keywords, and other free terms related to "questionnaires"; "hearing tests"; "mobile application"; software; "mass screening hearing"; "auditory perception"; and "auditory perceptual disorders" were used with Boolean operators (e.g. OR and AND) to combine searches. Additional information on the search strategies are provided on the Appendix 1. The lists of references of included studies were also hand-searched to identify additional relevant studies ${ }^{15}$. Experts were also consulted by email to improve search findings.

Studies of the accuracy screening instruments applied for identification of the CAPD were included. For this end, it was necessary that the study had compared CAPD screening instruments either already validated or with a battery of tests for the diagnosis 
of CAPD. The inclusion of studies had no restrictions regarding language, age, gender, and time of publication.

Studies excluded from the analysis were: 1 - Studies whose subjects had hearing loss; 2 - Studies presenting any other screening protocol, whose focus was not the CAPD; 3 - Studies not using the reference standard, which could be either a battery of behavioral tests for the auditory processing assessment, or instruments validated for the diagnosis; 4 - Studies not presenting accurate measurements (sensitivity and specificity), or not presenting sufficient data to calculate them; 5 - Case-control studies, cohort studies, clinical trials, conference summaries, personal opinions, congress annals, reviews, editorials, and letters to the editor; and 6 - Unavailable complete articles. Those criteria were applied on screening stage and full text analyses.

The search was conducted on December 12, 2018 and updated on August 17, 2020. The references were administered, and the duplicated files were removed with the help of the Mendeley $\odot$ software (2008 Glyph \& Cog, LLC.), version 1.19.4. The online data manager Rayyan.qcri (Rayyan, Qatar Computing Research Institute) ${ }^{16}$ was used to enable, between the reviewers, the blind reading of the titles and abstracts.

In the third phase of the review, four reviewers selected the articles blindly and independently. On the screening stage, these four reviewers examined the titles and abstracts of all the studies through the Rayyan.qcri (Rayyan, Qatar Computing Research Institute) ${ }^{16}$ applying eligibility criteria. Then the same four reviewers evaluated the full text with eligibility criteria. The four reviewers cleared any disagreement in both stages by discussing and getting to a mutual agreement. When they could not get to a consensus, the fifth reviewer was asked to make a final decision.

Two reviewers blindly and independently collected from the selected articles author, year and country of publication of the study, sample size, mean age in years, characteristics of the subjects and other alterations, screening instruments, auditory processing skills, sensitivity and specificity values, pass/fail criterion, and the diagnostic method used. Any disagreement was settled by discussion and mutual agreement between the two reviewers. The sixth author was involved, as necessary, to make possible for the final decision to be formulated.

\section{LITERATURE REVIEW}

The search on the databases returned 1,366 studies, as shown on the diagram (Figure 1). After the duplicated files had been removed, the first selection of 1,174 articles was conducted (stage 1), through the reading of title and/or abstract. Following the eligibility criteria, 1,144 studies were excluded. Of the 30 remaining articles, three could not be obtained, even though the authors of the articles had been contacted by e-mail in different days and hours to make possible for the articles to be obtained in full. Neither were the articles available in full text on the repositories to which the researchers' university of origin has access, nor was there availability for them to be acquired. The search on the grey literature identified 1,864 studies; the first 100 results from each database were taken into consideration in the initial title and abstract analysis. None of these met the eligibility criteria. It is also important to highlight that, after the reference lists had been sought through and the articles had been solicited to the experts, no additional study was included.

With the update of the searches, 114 were analyzed based on the title and abstract. Three articles met the eligibility criteria and went on to analyze the full text. Therefore, 33 articles passed on to the stage 2, when the full texts were read, and 28 of them were excluded following the same eligibility criteria (shown in Appendix 2). Lastly, five studies remained and were included in the qualitative analysis.

The five studies included had been published in the United States ${ }^{17}$, in Germany ${ }^{18}$, in the United Kingdom ${ }^{19,20}$ and in Hong Kong ${ }^{21}$. The sample size of the studies varied from 81 to 201 subjects, aged from 6 to 16 years.

The screening instruments used were a Screening Test for Auditory Processing Disorders (SCAN) ${ }^{17}$; auditory processing behavioral test battery ${ }^{18}$, Children's auditory performance scale (CHAPS) ${ }^{19}$, the SCAN-3 subtest Auditory Figure-Ground (AFG) in the signal/ noise relations of $+8 \mathrm{~dB}$ and $0 \mathrm{~dB}^{20}$, the Screening Test for Auditory Processing (STAP) and the Screening Checklist for Auditory Processing (SCAP) ${ }^{21}$. The pass/ fail criterion was presented in four articles, and they were the signal-noise relation of $0 \mathrm{~dB}$ in the $\mathrm{AFG}^{20}$; failing in two or more tests of the battery conducted, with score of 1 to $1.5 \mathrm{SD}$ below average ${ }^{19}$; the parameters recommended by Keith ${ }^{5}$, i.e., 1 SD below average composite score of the subtests ${ }^{18}$; and a cut-off score criteria of 6 on the SCAP. In the articles from $2000^{18}$ and $2014^{21}$, there was the need of support from another study to present this information ${ }^{5,22}$. It should be noted 


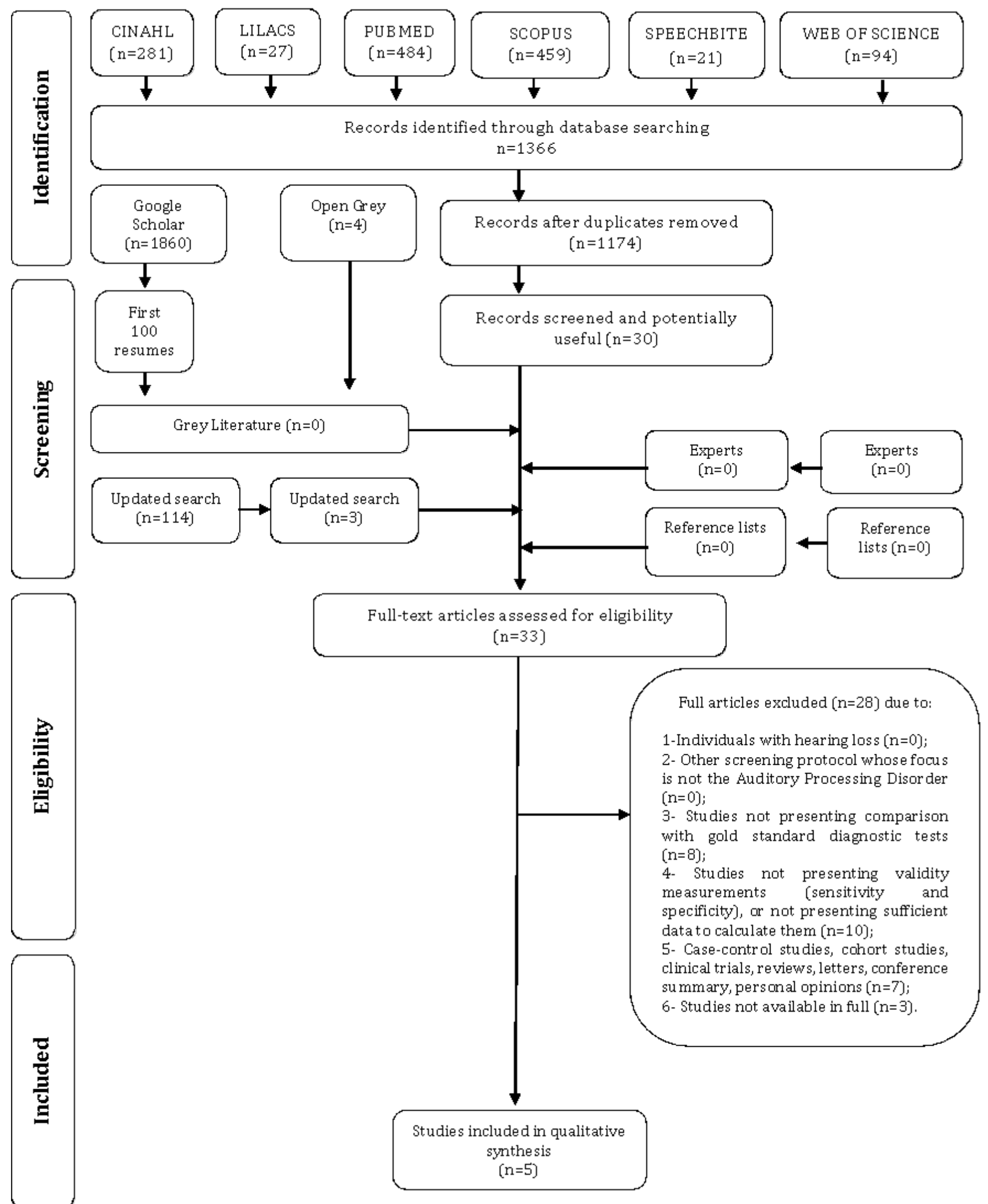

Figure 1. Flow diagram of literature search and selection criteria ${ }^{1}$ 
that article of $2014^{21}$ did not mention the parameters of the STAP.

All the studies achieved the primary outcome, proving the accuracy of the instruments analyzed. The values of sensitivity ranged from $42.1 \%$ to $97.2 \%$, whereas those of specificity reached between $65.5 \%$ and $100 \%$. The CAPD diagnostic methods observed were minimum batteries of behavioral tests aimed at assessing all the auditory processing skills, or the SCAN test battery aimed at diagnosing. The detailed characteristics of the studies included are shown in Table 1.

Table 1. Summary of descriptive characteristics and outcomes of interest of the included studies $(n=5)$

\begin{tabular}{|c|c|c|c|c|c|c|c|}
\hline $\begin{array}{l}\text { Author, year; } \\
\text { country }\end{array}$ & $\begin{array}{c}\text { Number of } \\
\text { subjects }(n), \\
\text { Mean age } \\
\text { (years) } \pm \text { SD }\end{array}$ & $\begin{array}{l}\text { Characteristics of the } \\
\text { subjects and other } \\
\text { alterations }\end{array}$ & Reference gold diagnostic method & Index test & $\begin{array}{l}\text { Definition of } \\
\text { positivity in the } \\
\text { screening test }\end{array}$ & Sensitivity & Specificity \\
\hline \multirow{4}{*}{$\begin{array}{l}\text { Ahmmed and } \\
\text { Ahmmed, } \\
\text { 2016; United } \\
\text { Kingdom }^{19}\end{array}$} & 109 & \multirow{4}{*}{$\begin{array}{c}\text { Male: } 67 \\
\text { Other alterations - NR }\end{array}$} & Batteries SCAN-C: FW, AFG $+8 \mathrm{~dB}, \mathrm{CW}$, & \multirow[t]{4}{*}{ CHAPS } & \multirow{4}{*}{$\begin{array}{c}\text { Failure in two or } \\
\text { more tests, from } \\
1 \text { to } 1.5 \text { SD below } \\
\text { average }\end{array}$} & \multirow[t]{4}{*}{$53.3 \%$} & \multirow[t]{4}{*}{$75 \%$} \\
\hline & $9.33 \pm 1.40$ & & CS and IMAP (assesses auditory & & & & \\
\hline & $6-11$ years & & cognitive function). & & & & \\
\hline & & & $\begin{array}{l}\text { Diagnostic criteria for CAPD: } \\
\text { performance } 1 \text { SD and } 1.5 \text { SD below the } \\
\text { mean in at least two CAPD tests } \\
\text { (i.e. SCAN-C and IMAP tests) }\end{array}$ & & & & \\
\hline \multirow{5}{*}{$\begin{array}{l}\text { Ahmmed, } \\
\text { 2017; United } \\
\text { Kingdom }^{20}\end{array}$} & \multirow{5}{*}{$\begin{array}{c}201 \\
10.5 \pm 2.8 \\
6-16 \text { years }\end{array}$} & \multirow{5}{*}{$\begin{array}{c}\text { Male: } 115 \\
\text { - Language disorder (17.4\%) } \\
\text { - ADHD (2.9\%) } \\
\text { - ADHD and language } \\
\text { disorder }(38.3 \%)\end{array}$} & \multirow{5}{*}{$\begin{array}{l}\text { Battery of SCAN-3 diagnostic tests: FW, } \\
\text { AFG }+8 \mathrm{~dB}, \mathrm{CW}, \mathrm{CS}, \mathrm{AFG} 0 \text {, TCS. } \\
\text { Diagnostic criteria for CAPD: } \\
\text { percentile score } \leq 10 \text { in two or more } \\
\text { SCAN-3 subtests }\end{array}$} & subtest of the & \multirow{5}{*}{$\begin{array}{l}\text { percentile score } \\
\leq 10 \text { on } \mathrm{AFG} \text { with } \\
\mathrm{S} / \mathrm{N} \text { ratio }=0\end{array}$} & \multirow[t]{4}{*}{$42.1 \%$} & \multirow[t]{4}{*}{$80 \%$} \\
\hline & & & & SCAN-3 battery - & & & \\
\hline & & & & $\begin{array}{l}\text { AFG with S/N ratio } \\
\quad=+8 \mathrm{~dB}\end{array}$ & & & \\
\hline & & & & & & & \\
\hline & & & & $\begin{array}{l}\text { subtest of the } \\
\text { SCAN-3 battery - } \\
\begin{array}{c}\text { AFG with S/N ratio } \\
=0 \mathrm{~dB}\end{array}\end{array}$ & & $56.3 \%$ & $100 \%$ \\
\hline \multirow{5}{*}{$\begin{array}{l}\text { Domitz, } \\
\text { Schow, } \\
\text { 2000; USA }{ }^{17}\end{array}$} & \multirow{5}{*}{$\begin{array}{c}81 \\
8-9 \text { years }\end{array}$} & \multirow{5}{*}{$\begin{array}{c}\text { Male: } 40 \\
\text { - Learning difficulty (14\%) } \\
\text { - ADHD (9\%) } \\
\text { - Language and speech } \\
\text { alterations (4\%) } \\
\text { - One or more overlapping } \\
\text { diagnoses }(20 \%) \\
\end{array}$} & \multirow{5}{*}{$\begin{array}{l}\text { Battery MAPA: mSAAT; Frequency pattern } \\
\text { tests; Dichotic Digits and Competing } \\
\text { Sentences. } \\
\text { Diagnostic criteria for CAPD: performance } \\
2 \text { SD below the mean in at least one test }\end{array}$} & \multirow[t]{5}{*}{ SCAN } & \multirow{5}{*}{$\begin{array}{c}\text { Parameters } \\
\text { recommended } \\
\text { by Keith (1986): } \\
\text { score of up to } \\
1 \text { SD below } \\
\text { composed score } \\
\text { average }\end{array}$} & \multirow[t]{5}{*}{$45 \%$} & \multirow[t]{5}{*}{$95 \%$} \\
\hline & & & & & & & \\
\hline & & & & & & & \\
\hline & & & & & & & \\
\hline & & & & & & & \\
\hline \multirow{13}{*}{$\begin{array}{l}\text { Kiese- } \\
\text { Himmel, } \\
\text { Nickisch, } \\
2015 \text {; } \\
\text { Germany }^{18}\end{array}$} & \multirow{13}{*}{$\begin{array}{c}178 \\
8.44 \pm 0.99 \\
7-10 \text { years }\end{array}$} & & Battery of auditory processing diagnostic & Mottier test & NR & $90.1 \%$ & $93.1 \%$ \\
\hline & & & behavioral tests (German). & & & & \\
\hline & & & $\begin{array}{l}\text { Diagnostic criteria for CAPD: } \\
\text { raw scores as the cut-off point based on } \\
\text { the maximum value of Youden's index }\end{array}$ & & & & \\
\hline & & & Mottier test: 17,5 & & & & \\
\hline & & & HSET IS subtest: 21,5 & HSET IS subtest & & $84.6 \%$ & $97.7 \%$ \\
\hline & & & PET ZFG subtest: 25,5 & PET ZFG subtest & & $84.6 \%$ & $79.3 \%$ \\
\hline & & & $\begin{array}{l}\text { Göttinger speech-in-noise } \\
\text { audiometry: } 82,5\end{array}$ & $\begin{array}{l}\text { Göttinger } \\
\text { speech-in-noise } \\
\text { audiometry }\end{array}$ & & $71.4 \%$ & $88.5 \%$ \\
\hline & & & Dichotic words comprehension: 82,5 & $\begin{array}{l}\text { Dichotic words } \\
\text { comprehension }\end{array}$ & & $63.7 \%$ & $95.4 \%$ \\
\hline & & & HLAD phoneme identification: 18,5 & $\begin{array}{l}\text { HLAD phoneme } \\
\text { identification }\end{array}$ & & $81.3 \%$ & $74.4 \%$ \\
\hline & & & Step (PaTsy): 80,0 & Step (PaTsy) & & $80.5 \%$ & $74.4 \%$ \\
\hline & & & HLAD phoneme differentiation: 19,5 & $\begin{array}{l}\text { HLAD phoneme } \\
\text { differentiation }\end{array}$ & & $63.7 \%$ & $81.6 \%$ \\
\hline & & & $\begin{array}{l}\text { Monaural threshold classification } \\
\text { (PaTsy): } 225,5\end{array}$ & $\begin{array}{l}\text { Monaural threshold } \\
\text { classification } \\
\text { (PaTsy) }\end{array}$ & & $75.9 \%$ & $65.5 \%$ \\
\hline & & & HLAD phoneme analysis: 8,5 & $\begin{array}{l}\text { HLAD phoneme } \\
\text { analysis }\end{array}$ & & $64.8 \%$ & $73.5 \%$ \\
\hline
\end{tabular}




\begin{tabular}{|c|c|c|c|c|c|c|c|}
\hline $\begin{array}{l}\text { Author, year; } \\
\text { country }\end{array}$ & $\begin{array}{c}\text { Number of } \\
\text { subjects }(\mathrm{n}) \text {, } \\
\text { Mean age } \\
\text { (years) } \pm \text { SD }\end{array}$ & $\begin{array}{l}\text { Characteristics of the } \\
\text { subjects and other } \\
\text { alterations }\end{array}$ & Reference gold diagnostic method & Index test & $\begin{array}{l}\text { Definition of } \\
\text { positivity in the } \\
\text { screening test }\end{array}$ & Sensitivity & Specificity \\
\hline \multirow{9}{*}{$\begin{array}{l}\text { Yathiraj; } \\
\text { Maggu, } \\
\text { 2014; Hong } \\
\text { Kong }^{21}\end{array}$} & \multirow{9}{*}{$\begin{array}{c}152 \\
8-13 \text { years }\end{array}$} & \multirow{9}{*}{$\begin{array}{l}\text { Normal hearing } \\
\text { Distribution of subjects } \\
\text { according to age and other } \\
\text { alterations - NR }\end{array}$} & \multirow{3}{*}{$\begin{array}{l}\text { Battery of diagnostic tests: SPIN-IE, DCV, } \\
\text { GDT and RAMST-IE. }\end{array}$} & STAP & & \multirow[t]{7}{*}{$76.6 \%$} & \multirow[t]{7}{*}{$72 \%$} \\
\hline & & & & Subtests: & $\mathrm{RE} / \mathrm{LE}$ & & \\
\hline & & & & - SPIN & 6 / 6 words & & \\
\hline & & & $\begin{array}{l}\text { Children who failed on only one diagnostic } \\
\text { test - performance } 2 \text { SD below the mean }\end{array}$ & - DCV & $\begin{array}{c}4 \text { / } 4 \\
\text { consonant-vowel } \\
\text { pairs per ear }\end{array}$ & & \\
\hline & & & \multirow[t]{5}{*}{$\begin{array}{l}\text { Children who failed more than one } \\
\text { diagnostic test - performance } 1 \mathrm{SD} \\
\text { below the mean }\end{array}$} & & $\begin{array}{l}2 \text { consonant- } \\
\text { vowel pair } \\
\text { answered } \\
\text { simultaneously }\end{array}$ & & \\
\hline & & & & $-G D$ & $\begin{array}{c}4 \quad / 4 \\
\text { triads of } 300 \\
\text { msec white noise }\end{array}$ & & \\
\hline & & & & $-A M$ & 12 words & & \\
\hline & & & & SCAP & Cut-off score $=6$ & $74.1 \%$ & $50 \%$ \\
\hline & & & & SCAP + STAP & $\begin{array}{l}\text { Parameters } \\
\text { already presented } \\
\text { above }\end{array}$ & $83.8 \%$ & $76.2 \%$ \\
\hline
\end{tabular}

Captions: S/N - Signal/Noise; NR - Not report; ADHD - Attention-deficit/hyperactivity disorder; AFG - Auditory Figure-Ground (Speech-in-Noise); FW - Filtered Words, CW - Competing Words, CS - Competing Sentences, TCS - Time-Compressed Sentences; CHAPS - Children's Auditory Performance Scale; IMAP - Institute of Hearing Research Multicenter Auditory Processing; SCAN - A Screening Test for Auditory Processing Disorders; MAPA - Multiple Auditory Processing Assessment;

mSAAT - monaural Selective Auditory Attention Test; STAP - Screening Test for Auditory Processing; SPIN - Speech Perception in Noise; DCV - Dichotic Consonant Vowel; GD - Gap Detection; AM - Auditory Memory; SPIN-IE - Speech Perception in Noise in Indian English; GDT - Gap Detection Test; RAMST-IE - Revised Auditory Memory and Sequencing test in Indian English; SCAP - Screening Checklist for Auditory Processing.

The five studies included in this review used different procedures for screening auditory processing and were conducted with children. There was no homogeneity in the presentation of the pass/fail criterion, or in the gold reference test used to establish the presence of the CAPD.

All the articles included presented the sensitivity and specificity measurements of the screening instruments ${ }^{17-21}$. The instruments used were two versions of the SCAN ${ }^{17,20}$, Mottier test ${ }^{18}$, STAP and SCAP used separately and in combination ${ }^{21}$, and the questionnaire CHAPS $^{19}$, in spite of the questionnaires, especially those developed more recently based on psychometric characteristics, being promising screening instruments to detect subjects at risk of CAPD ${ }^{6}$. A systematic review with questionnaires for Brazilian Portuguese found only one validated instrument, the APDQ, indicating that there was a rate of $100 \%$ in the sensitivity and specificity measurements ${ }^{11}$. This datum indicates that it is a tool apt to detect all the subjects who actually have CAPD (sensitivity), as well as exclude the subjects without alteration (specificity) ${ }^{23}$.

Despite this, the values of sensitivity and specificity of the SCAP may reflect that the use of questionnaires by other professionals, such as teachers, tends to correctly identify CAPD in suspected children. However, they are likely to be over-referred. Screening becomes more accurate when there is an association between two types of tools, such as the use of tests that involve recorded sound stimuli21.

Sensitivity and specificity vary across studies. Nevertheless, some studies have used similar instruments, they could belong to different categories, such as the SCAN ${ }^{16,19}$ which has variations. Probably the different characteristics from tests can interfere on the task executed by the child, and consequently on sensitivity and specificity measures. CAPD complex nature ${ }^{1}$ could reflect different results for different symptoms, too.

Five instruments applied in children for CAPD screening were identified: CHAPS, AFG, SCAN, Mottier, SCAP and STAP. The specificity of all the instruments CHAPS, AFG, SCAN, Mottier test, STAP and the associated use between SCAP and STAP were higher than $70 \%$, but just the Mottier and STAP test, and SCAP showed sensibility higher than $70 \%$.

The Mottier test was the instrument with better specificity and sensibility. This test assesses memory, which is only worked on in the STAP tests. This gives greater sensitivity to the instrument since this is one of the most 
affected skills in this population ${ }^{21}$. In addition, memory is linked to sequences of meaningless syllables which makes the test more difficult.

Among the articles included in this review, it is possible to verify that there is no strong relationship between questionnaires and CAPD screening tests. Questionnaires can provide information on comorbidities and behavioral issues that allow them to know the individual in the educational, social and communicative contexts. Meanwhile, the performance-based screening tools present varied tasks that focus on different listening skills and some of them may have more consistent results to determine the CAPD or the need for a detailed behavioral assessment ${ }^{24}$.

The description of the methodological procedures and the pass/fail criterion used in the studies was not homogeneous either. Kiese-Himmel; Nickisch ${ }^{18}$ did not present the pass/fail criterion used, making it difficult for the instrument to be concisely analyzed, and the methodological procedures to be reproduced by an independent author. The remaining four articles coherently described the criterion used 17,19-21. However, they diverged from one another, as the tests present their particularities, related to the use of stimuli with different acoustic characteristics and tasks. Despite the SCAN being used in two studies ${ }^{17,20}$, the manner of assessment and the parameters of analysis were not the same. Domitz; Schow ${ }^{17}$ propose the screening to be conducted with all the subtests, based on the recommendations of the author of the instrument ${ }^{5}$. Ahmmed ${ }^{20}$, in his turn, deals only with the use of the Speech-in-Noise subtest, studying the performance of the subjects in the signal/noise relations of $0 \mathrm{~dB}$ and $+8 \mathrm{~dB}$ to define which of these would better reflect the actual listening difficulties.

The age range of the participants of the included studies encompass school age, the youngest being six years old ${ }^{19,20}$, and the oldest, 16 years old ${ }^{19}$. Such proximity reiterates the relevance of studies with this public, since the screening can provide important information for the diagnosis. In the adult public, there is greater probability that the signs and symptoms of CAPD have not been identified or could be confounded with other health conditions. However, the results of this review evidenced the poor studies with this public, that need an adequate instrument to screening too.

Regarding the reference standard to determine the presence or absence of CAPD, there was no homogeneity. This is certainly a reflection of the complex and heterogeneous nature of the $\mathrm{CAPD}^{1,25}$ and, as a consequence, of its diagnosis, whose definition presents diverging concepts.

The recommendations concerning the diagnosis indicate that the different categories composing the auditory processing - temporal processing, dichotic listening, low-redundancy speech perception, and binaural interaction - should be evaluated ${ }^{26}$. The German study that investigated the accuracy of different combinations of the tests concludes that, for the diagnosis, the ideal is the combination of the ten tests of the battery studied ${ }^{18}$. Following the same line of investigation, one study from the United Kingdom uses as gold standard the SCAN- $3^{20}$, whereas the other study from the United Kingdom uses the SCAN-C battery as diagnostic criterion ${ }^{19}$. Although these two studies use SCAN, different versions are used, with distinct diagnostic criteria, even though the tests are similar. Another study used the MAPA battery ${ }^{17}$, and another, a combination of tests ${ }^{21}$, as recommended for the diagnostic assessment ${ }^{26}$.

A lot of points are discussed about the definition and diagnosis of $C A P D^{2,27,28}$. It cannot yet be precisely stated that the CAPD is characterized as a solely auditory deficit ${ }^{2}$, since the literature evidences that the intelligence, memory, attention and language characteristics in children with CAPD overlap the same characteristics in children diagnosed with specific language impairment, dyslexia, attention deficit hyperactivity disorder (ADHD) and learning difficulty. This supports the idea that the various diagnosis of disorders interrelates, forming a sort of spectrum, instead of distinct alterations, with well-defined characteristics ${ }^{29}$.

There is also the premise that the CAPD goes beyond a disorder, its symptoms being a marker for the Neurodevelopmental Syndrome, which associates various auditory, speech, attention, memory, and behavioral difficulty markers. Depending on the severity and predominance of one or more markers, the child would manifest a unique development profile, with modulated unfoldment through the genetic composition, the environment to which the child is exposed, the age, and the academic demands ${ }^{30}$.

For Moore ${ }^{27}$, it is implausible that children with auditory difficulties (auditory inabilities, in spite of audiometry within standard normality) present a disorder in the central auditory function and it can be diagnosed only through a combination of tests. This occurs because the symptoms clinically reported in the subjects do not follow logically along with the tests used, or with an intervention based on evidence ${ }^{27}$. On 
the other hand, a second line of thought states that the term "auditory difficulties" is not specific enough, just as it does not contribute to the differential diagnosis. Due to its complexity, CAPD needs a thorough assessment through the central auditory processing tests and the multidisciplinary insight for the differential diagnosis to be precise and to manage to identify comorbidities, thus maximizing an effective intervention, directed to the specific processes identified through the diagnostic battery ${ }^{26-28}$.

In spite of this, all the studies included at least one test that assesses the abilities of hearing integration and/or target-to-masker listening ${ }^{17,19-21}$. Filtered speech was used ${ }^{17,19}$, as well as speech in noise ${ }^{21}$, and figureground $^{20}$, encompassing the degraded speech ${ }^{1,25,26}$.

Given the particularities of each instrument, it is challenging to think which pass-failure criterion would be the most relevant. For STAP ${ }^{21}$, whose criteria are based on existing diagnostic tests, there is greater reliability in the result when the total score has correct answers above $50 \%$ of the stimuli presented in each subtest. The $\operatorname{SCAN}^{17,20}$, which had lower sensitivity values, presented parameters involving um standard deviation below the average of the composite score ${ }^{17}$ and the percentile score $\leq 10$ in the AFG subtest, both determined by reflecting more adequately to the real hearing difficulties. This comparison is also reinforced with the SCAP ${ }^{21}$ and $\mathrm{CHAPS}^{19}$ questionnaires. In the first, the cut-off point the score was six, with a score for each symptom related to CAPD ${ }^{21}$, while the second is based on a score below 1.5 standard deviation ${ }^{19}$.

Attention should also be called to the fact that, of the 28 excluded articles, seven were so because of the methodological design that diverged from the accuracy study, which was the focus of this review. Ten articles were excluded for not presenting all the accuracy measurements; and eight did not report the comparison with a battery of auditory processing diagnostic tests, considered as the reference standard assessment. This reflects the shortage of studies in audiology with methodological rigor to assess the accuracy of the CAPD screening instruments, and the need of primary studies presenting this scope and overcoming the difficulties with the diagnostic and the establishment of the reference standard. Only after this it will be possible to broaden the discussions and present more effective evidence, strengthening the importance of CAPD screening in the clinical context.

The heterogeneity found in the gold reference standard test and in the index test are presented here as limitations to this study, since it makes the comparison and the conclusion less effective. Nevertheless, it reflects the complexity of the CAPD, and points to the need for further primary studies with rigorous methodology in order for them to be replicated, thus making comparisons easier. A methodological limitation of this review was the lack of access to three studies on the second phase, as they were unavailable in full text version, though all the possibilities had been tried, even requesting the corresponding author to provide the article.

Another limitation to the study was exactly the non-homogeneity of the pass/fail criteria to consider the CAPD in the screening instruments and in the diagnostic criteria. These two points wind up making evident the fragility in this field of knowledge; it is thus necessary to invest in primary studies presenting sturdier scientific methodology so as to bring about clearer and more valid scientific contributions to the clinical context of the practice of audiology in the field of the CAPD.

\section{CONCLUSION}

The CAPD screening test with the best accuracy was the Mottier test. There was no homogeneity in the presentation of the pass/fail criterion, or in the gold reference test used to establish the presence of the CAPD. The specificity of the instruments identified (CHAPS, AFG, SCAN, Mottier test, STAP and the associated use between SCAP and STAP) were higher than $70 \%$, but just the Mottier and STAP test, and SCAP showed sensibility higher than $70 \%$.

\section{ACKNOWLEDGEMENT}

Special thanks to the colleagues of the Laboratory of Technological Innovation in Health, Onofre Lopes University Hospital, Federal University of Rio Grande do Norte, for all the support and useful contributions throughout the process. We also thank Claudio Lingerfelt for the great work in translating the manuscript and Wesam Ashour for reviewing the translated manuscript. 


\section{REFERENCES}

1. British Society of Audiology. Position Statement and Practice Guidance Auditory Processing Disorder (APD). Br Soc Audiol. [journal on the internet] 2018. [accessed on 2021 March 3] [about 19p.] Available at: https://www.thebsa.org.uk/ wp-content/uploads/2018/02/Position-Statementand-Practice-Guidance-APD-2018.pdf

2. Neijenhuis K, Campbell NG, Cromb M, Luinge MR, Moore DR, Rosen S et al. An evidence-based perspective on "misconceptions" regarding pediatric auditory processing disorder. Front Neurol. 2019;10:287. DOI:10.3389/fneur.2019.00287.

3. ICD-10-CM Codes. 2020 ICD-10-CM Diagnosis Code H93.25: Central auditory processing disorder. [accessed on 2021 March 3] Available at: https:// www.icd10data.com/ICD10CM/Codes/H60-H95/ H9O-H94/H93-/H93.25.

4. Musiek F, Gollegly KM, Ross MK. Profile of types of central auditory processing disorders in children with learning disabilities. $\mathrm{J}$ Commun. 1985;9(1):43-63. DOI: 10.1016/j.ijporl.2007.12.007.

5. Keith RW. SCAN: A Screening Test for Auditory Processing Disorders. San Antonio, TX: The Psychological Corporation, Harcourt, Brace, Jovanovich, Inc. 1986.

6. O'Hara B, Mealings K. Developing the auditory processing domains questionnaire (APDQ): a differential screening tool for auditory processing disorder. Int J Audiol. 2018;57(10):764-75. DOI: 10.1080/14992027.2018.1487087.

7. Smoski WJ, Brunt MA, Tannahill JC. Children's auditory performance scale. Tampa, FL: Educational Audiology Association. 1992.

8. Barker MD, Purdy SC. An initial investigation into the validity of a computer-based auditory processing assessment (Feather Squadron). Int J Audiol. 2016;55(3):173-83. DOI: 10.3109/14992027.2015.1074734.

9. Amaral MIR, Carvalho NG, Colella-Santos MF. Computer-based central auditory processing screening for school-age children (audBility): an initial investigation. CoDAS. 2019;31(2):1-11. DOI: 10.1590/2317-1782/20182018157.

10. Pereira LD. Processamento auditivo. Temas Desenvol. 1993;2(11):7-14. DOI: 10.1590/ S1808-86942011000300015.
11. Volpatto FL, Rechia IC, Lessa AH, Soldera CLC, Ferreira MID da C, Machado MS. Questionnaires and checklists for central auditory processing screening used in Brazil: a systematic review. Braz J Otorhinol. 2019;85(1):99-110. DOI:10.1016/j. bjorl.2018.05.003.

12. Carvalho NG, Ubiali T, Amaral MIR, ColellaSantos MF. Procedures for central auditory processing screening in schoolchildren. Braz $\mathrm{J}$ Otorhinolaryngol. 2019;85(3):319-28 .

13. Musiek F, Gollegly KM, Lamb LE, Lamb P. Selected issues in screening for central auditory processing dysfunction. Semin Hear. 1990;11(4):372-84.

14. Lessler K. Health and education screening of school-age children - Definition and objectives. Am J Public Health. 1972;62(2):191-8. DOI: 10.2105 / ajph.62.2.191

15. Greenhalgh T, Peacock R. Effectiveness and efficiency of search methods in systematic reviews of complex evidence: audit of primary sources. BMJ. 2005;331(7524):1064-5. DOI:10.1136/ bmj.38636.593461.68.

16. Ouzzani M, Hammady H, Fedorowicz Z, Elmagarmid A. Rayyan-a web and mobile app for systematic reviews. Syst Rev. 2016;5(1):1-10. DOI:10.1186/s13643-016-0384-4.

17. Domitz DM, Schow RL. A new CAPD Battery-Multiple Auditory Processing Assessment. Am J Audiol. 2000;9(2):101-11. DOI:10.1044/1059-0889(2000/012).

18. Kiese-Himmel C, Nickisch A. Diagnostic accuracy of a test set to classify children with auditory processing disorders (APD). Laryngo Rhino Otol. 2015;94(6):373-7. DOI: 10.1055/s-0034-1387766.

19. Ahmmed AU, Ahmmed AA. Setting appropriate pass or fail cut-off criteria for tests to reflect real life listening difficulties in children with suspected auditory processing disorder. Int $\mathrm{J}$ Pediatr Otorhinolaryngol. 2016;84:166-73. DOI:10.1016/j. ijporl.2016.03.014.

20. Ahmmed AU. Intelligibility of degraded speech and the relationship between symptoms of inattention, hyperactivity/impulsivity and language impairment in children with suspected auditory processing disorder. Int J Pediatr Otorhinolaryngol. 2017;101:78-85. DOI: 10.1016/j.ijporl.2017.08.010 
21. Yathiraj A, Maggu AR. Validation of the Screening Test for Auditory Processing (STAP) on school-aged children. Int J Pediatr Otorhinolaryngol. 2014;78(3):479-88. DOI:10.1016/j.ijporl.2013.12.025.

22. Yathiraj A, Maggu AR. Screening Test for Auditory Processing (STAP): a preliminary report. J Am Acad Audiol. 2013;24(9):867-78. DOI:10.3766/ jaaa.24.9.10.

23. Hochman B, Nahas FX, Oliveira Filho RS, Ferreira LM. Desenhos de pesquisa. Acta Cir Bras. 2005;20(2):2-8.

24. Shaikh MA, Baker B, Levya A. Comparison of Questionnaire-Based and Performance-Based Screening Tools as predictors of auditory processing disorder. Am $\mathrm{J}$ Audiol. [journal on the internet] 2020 [accessed on 2021 March 3]; 29(2):143-51. Available at: https://doi. org/10.1044/2019_AJA-19-00025

25. ASHA. American Speech-Language-Hearing Association. (Central) Auditory Processing Disorders. [Homepage on the Internet] 2005. [accessed on 2021 March 3]. Available at: http:// www.asha.org/members/deskref-journals/deskref/ default.

26. AAA. American Academy of Audiology Clinical Practice Guidelines: Diagnosis, Treatment and Management of Children and Adults with Central Auditory Processing Disorder. Am Acad Audiol. [journal on the internet] 2010 [accessed on 2021 March 3]; 1-51p. Available at: https://audiology-web. s3.amazonaws.com/migrated/CAPD Guidelines 8-2010.pdf_539952af956c79.73897613.pdf

27. Moore DR. Guest Editorial: Auditory processing disorder. Ear Hear. 2018;39(4):617-20. DOI: 10.1097/AUD.0000000000000582.

28. Iliadou V, Chermak GD, Bamiou DE, Rawool VW, Ptok M, Purdy S et al. Letter to the editor: an affront to scientific inquiry RE: Moore DR. (2018) Editorial: Auditory processing disorder. Ear Hear. 2018;39(6):1236-42. DOI:10.1097/ AUD.0000000000000644.

29. de Wit E, van Dijk P, Hanekamp S, Visser-Bochane MI, Steenberg B, van der Schans CP et al. Same or different: the overlap between children with auditory processing disorders and children with other developmental disorders: a systematic review. Ear Hear. 2018;39(1):1-19. DOI: 10.1097/ AUD.0000000000000479.
30. Moore DR, Hunter LL. Auditory processing disorder (APD) in children: a marker of neurodevelopmental syndrome. Hear Balance Commun. 2013;11(3):160-7. DOI: 10.3109/21695717.2013.821756. 


\section{APPENDIX 1 \\ Database search strategy}

\begin{tabular}{|c|c|}
\hline Database & Search (December $12^{\text {th }} 2018$; updated on August $17^{\text {th }}, 2020$ ) \\
\hline CINAHL & 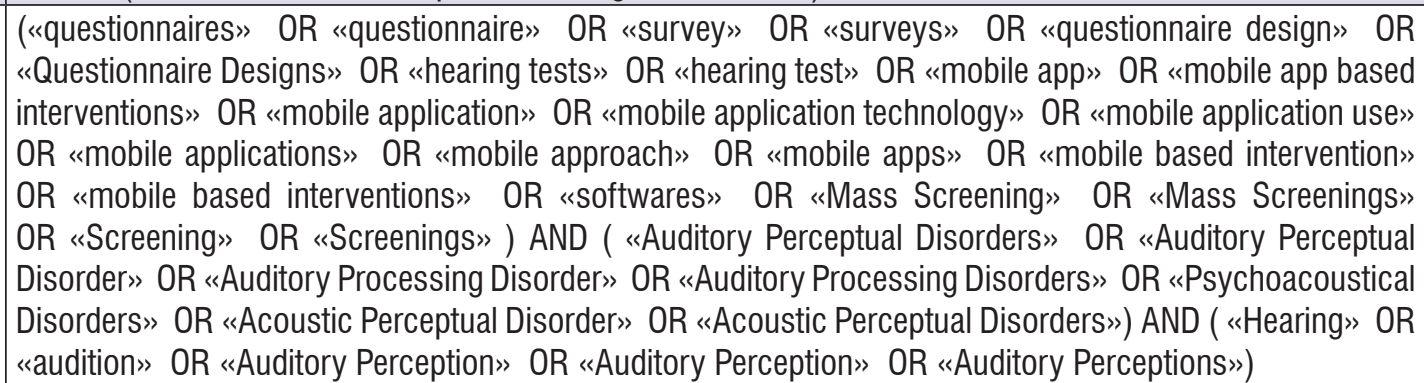 \\
\hline LILACS & $\begin{array}{l}\text { questionnaires OR Surveys OR Encuestas OR Cuestionarios OR inquéritos OR questionários OR Software OR } \\
\text { «Programas Informáticos» OR "Mass Screening" OR "tamizaje masivo" OR "programas de rastreamento" } \\
\text { and «Auditory Perceptual Disorders» OR «Trastornos de la Percepción Auditiva» OR «Transtornos da } \\
\text { Percepção Auditiva» }\end{array}$ \\
\hline PubMed/Medline & 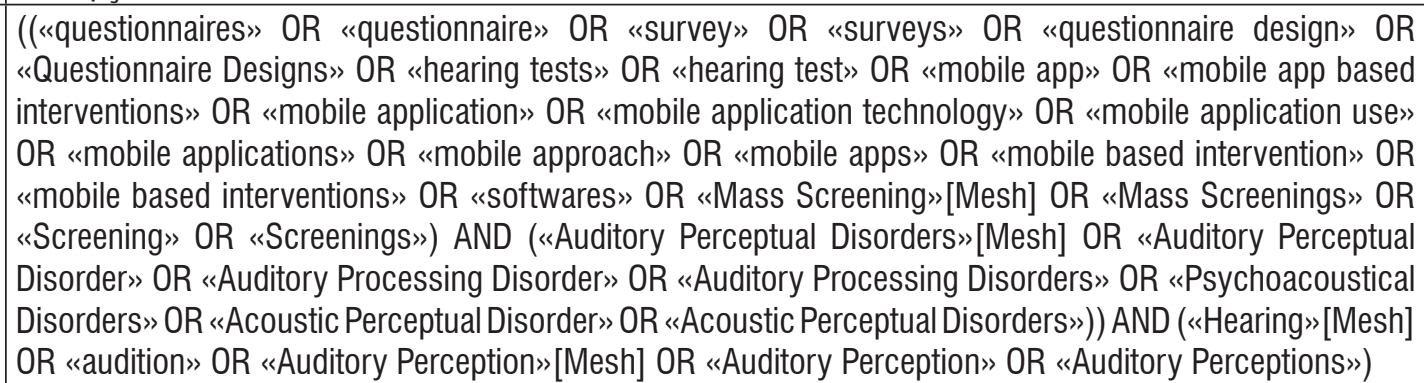 \\
\hline Scopus & $\begin{array}{l}\text { ("questionnaires" OR "questionnaire" OR "surveys" OR "questionnaire design" OR "hearing tests" OR } \\
\text { "hearing test" OR "mobile app based interventions" OR "mobile application" OR "Mass Screening" } \\
\text { OR "Mass Screenings" OR "Screening" OR "Screenings") AND ("Auditory Perceptual Disorders" OR } \\
\text { "Auditory Perceptual Disorder" OR "Auditory Processing Disorder" OR "Auditory Processing Disorders" OR } \\
\text { "Psychoacoustical Disorders" OR "Acoustic Perceptual Disorder" OR "Acoustic Perceptual Disorders") AND } \\
\text { ("Hearing" OR "audition" OR "Auditory Perception" OR "Auditory Perception" OR "Auditory Perceptions") }\end{array}$ \\
\hline Speechbite & $\begin{array}{l}\text { screening AND hearing } \\
\text { Option } 2 \text { - questionnaires OR survey OR hearing test OR mass screening AND hearing AND auditory } \\
\text { perceptual disorders OR auditory processing disorders }\end{array}$ \\
\hline Web of Science & $\begin{array}{l}\text { («questionnaires» OR «questionnaire» OR «survey» OR «Surveys» OR «questionnaire design» OR } \\
\text { «Questionnaire Designs» OR «hearing tests» OR «hearing test» OR «mobile app» OR «mobile app based } \\
\text { interventions» OR «mobile application» OR «mobile application technology» OR «mobile application use» } \\
\text { OR «mobile applications» OR «mobile approach» OR «mobile apps» OR «mobile based intervention» } \\
\text { OR «mobile based interventions» OR «Softwares» OR «Mass Screening» OR «Mass Screenings» OR } \\
\text { «Screening» OR «Screenings») AND («Auditory Perceptual Disorders» OR «Auditory Perceptual Disorder» } \\
\text { OR «Auditory Processing Disorder» OR «Auditory Processing Disorders» OR «Psychoacoustical Disorders» } \\
\text { OR «Acoustic Perceptual Disorder» OR «Acoustic Perceptual Disorders») AND («Hearing» OR «audition» } \\
\text { OR «Auditory Perception» OR «Auditory Perception» OR «Auditory Perceptions») }\end{array}$ \\
\hline Google Scholar & $\begin{array}{l}\text { Questionnaires OR questionnaire OR survey OR surveys OR «hearing tests» OR «hearing test» OR “mass } \\
\text { screening" OR screening AND hearing OR audition OR «Auditory Perception» OR «Auditory Perceptions» } \\
\text { AND «Auditory Perceptual Disorders» }\end{array}$ \\
\hline Open Grey & cessing Disorders» \\
\hline
\end{tabular}




\section{APPENDIX 2}

\section{Excluded articles and reasons for exclusion $(n=28)$}

\begin{tabular}{|l|c|}
\hline Author, Year & Reason for exclusion \\
\hline${ }^{1}$ Abramson, Lloyd (2016) & 5 \\
\hline${ }^{2}$ Amos, Humes (1998) & 4 \\
\hline${ }^{3}$ Arnott, Henning, Wilson (2014) & 6 \\
\hline${ }^{4}$ Barry et al. (2015) & 5 \\
\hline${ }^{5}$ Carlin, Saniga (1997) & 3 \\
\hline${ }^{6}$ Emerson et al. (1997) & 6 \\
\hline${ }^{7}$ Garbaruk et al. (2018) & 5 \\
\hline${ }^{8}$ Lucas et al. (2007) & 5 \\
\hline${ }^{9}$ Marriage et al. (2001) & 5 \\
\hline${ }^{10}$ Meister, Wedel, Walger (2004) & 4 \\
\hline${ }^{11}$ Moncrieff, Miller, Hill (2018) & 3 \\
\hline${ }^{12}$ Mourad et al. (2015) & 4 \\
\hline${ }^{3}$ Nickisch et al. (2005) & 4 \\
\hline${ }^{14}$ Nickisch et al. (2006) & 4 \\
\hline${ }^{15}$ Nunes, Pereira e Carvalho (2013) & 3 \\
\hline${ }^{16}$ Obuchi, Kaga (2019) & 3 \\
\hline${ }^{17}$ 'Hara, Mealings (2018) & 5 \\
\hline${ }^{18}$ Preclik et al. (2008) & 6 \\
\hline${ }^{19}$ Rickard, Smales, Rickard (2013) & 4 \\
\hline${ }^{20}$ Rutkowska, Lobaczuk-Sitnik, Kosztyla-Hojna (2017) & 3 \\
\hline${ }^{21}$ Shaikh, Baker and Levya (2020) & 3 \\
\hline${ }^{22}$ Skarzynski et al. (2015) & 4 \\
\hline${ }^{23}$ Sofokleous et al. (2020) & 3 \\
\hline${ }^{24}$ Strange, Zalewski, Waibel-Duncan (2009) & 4 \\
\hline${ }^{25}$ Vaidyanth, Yathiraj (2014) & 3 \\
\hline${ }^{26}$ Wilson et al. (2011) & 5 \\
\hline${ }^{27}$ Yathiraj, Maggu (2013) & 5 \\
\hline${ }^{28}$ Yathiraj, Maggu (2013) & 3 \\
\hline
\end{tabular}

Captions: 1- Individuals with hearing loss; 2- Other screening protocol whose focus is not the Auditory Processing Disorder; 3- Studies not presenting comparison with gold standard diagnostic tests; 4- Studies not presenting validity measurements (sensitivity and specificity), or not presenting sufficient data to calculate them; 5- Casecontrol studies, cohort studies, clinical trials, reviews, letters, conference summary, personal opinions; 6- Studies not available in full.

\section{REFERENCES}

1. Abramson MK, Lloyd PJ. Development of a Pitch Discrimination Screening Test for Preschool Children. J Am Acad Audiol. 2016;27(4):281-92. D0I: 10.3766/ jaaa.14052.

2. Amos NE, Humes LE. SCAN test-retest reliability for first- and third-grade children. J Speech Lang Hear Res. 1998 Aug;41(4):834-45.

3. Arnott WL, Henning CA, Wilson WJ. Screening and assessing for (central) auditory processing disorder and the role of the speech-language pathologist. J Clin Pract Speech-Language Pathol. 2014;16(2):66-72.

4. Barry JG, Tomlin D, Moore DR, Dillon H. Use of Questionnaire-Based Measures in the Assessment of Listening Difficulties in School-Aged Children. Ear Hear. 2015;36(6):e300-13

5. Carlin MF, Saniga RD. Teachers' perception of auditory problems and the SCAN. Percept Mot Skills. 1997 Aug;85(1):245-6. D0l:10.2466/pms.1997.85.1.245.

6. Emerson MF, Candrall KK, Seikel FT, Chermak GD. Observations on the use of SCAN to identify children at risk for central auditory processing disorder... Screening Test for Auditory Processing Disorders. Lang Speech Hear Serv Sch. 1997;28(1):43-9.

7. Garbaruk ES, Goykhburg MV, Warzybok A, Tavartkiladze GA, Pavlov PV, Kollmeier B. The application of the screening questionnaires for the diagnostics of the central auditory processing disorders in the pediatric practice. Vestn Otorinolaringol. 2018:83(4):43-50.

8. Lucas PA, Zacare CC, Alves Filho OC, Amantini RCB, Bevilacqua MC, Zaidan E. Scan: Performance profile of children with seven to eight years. Pro-Fono R. Atual. Cientif. 2007:19(4):370-3.

9. Marriage J, King J, Briggs J, Lutman ME. The reliability of the SCAN test: results form a primary school population in the UK. Br J Audiol. 2001;35(3):199-208. DOI: $10.1080 / 00305364.2001 .11745237$.

10. Meister H, von Wedel H, Walger M. Psychometric evaluation of children with suspected auditory processing disorders (APDs) using a parent-answered survey. Int $J$ Audiol. 2004 Sep;43(8):431-7.

11. Moncrieff D, Miller E, Hill E. Screening Tests Reveal High Risk Among Adjudicated Adolescents of Auditory Processing and Language Disorders. J Speech, Lang Hear Res [journal on the Internet]. 2018 [acessed on March 3 ${ }^{\text {rd }}$, 2021]; 61(4):924-35. Available at: DOl:10.1044/2017_JSLHR-H-17-0098.

12. Mourad M, Hassan M, El-Banna M, Asal S, Hamza Y. Screening for auditory processing performance in primary school children. J Am Acad Audiol. 2015;26(4):35569. DOI: $10.3766 /$ jaaa.26.4.4 
13. Nickisch A, Kiese-Himmel C, Schönweiler R, Gross M, Radü HJ. Zusammenhänge zwischen "anamnesebogen für auditive verarbeitungs- und wahrnehmungsstörungen” und „Heidelberger lautdifferenzierungste. Laryngorhinootologie. 2005;84(7):487-92. DOI 10.1055/s-2005-861021.

14. Nickisch A, Heuckmann C, Burger T, Massinger C. Münchner Auditiver Screeningtest für Verarbeitungs-und Wahrnehmungsstörungen (MAUS). Laryngorhinootologie. 2006;85(4):253-9. DOI 10.1055/s-2005-870565.

15. Nunes CL, Pereira LD, Carvalho GS. Scale of Auditory Behaviors and auditory behavior tests for auditory processing assessment in Portuguese children. CoDAS. 2013;25(3):209-15.

16. Obuchi C, Kaga K. Development of a questionnaire to assess listening difficulties in adults with auditory processing disorder. Hear Balanc Commun. 2019;18(1):29-35. DOI:10.1080/21695717.2019.1663055.

17. O'Hara B, Mealings K, O'Hara B, Mealings K. Developing the auditory processing domains questionnaire (APDQ): a differential screening tool for auditory processing disorder. Int J Audiol. 2018;57(10):764-75. DOl: 10.1080/14992027.2018.1487087.

18. Preclik M, Rosanowski F, Dollinger M, Eysholdt U, Kummer P. Anamnesebogen für auditive Verarbeitungs- und Wahrnehmungsstörungen. HNO. 2008;56(6):638-44. DOl 10.1007/s00106-008-1753-7.

19. Rickard NA, Smales CJ, Rickard KL. A computer-based auditory sequential pattern test for school-aged children. Int J Pediatr Otorhinolaryngol. 2013;77(5):838-42. DOI:10.1016/.i.jporl.2013.02.024.

20. Rutkowska J, Łobaczuk-Sitnik A, Kosztyła-Hojna B. Application of Brain-Boy Universal Professional in preliminary assessment of auditory processing disorder [Zastosowanie Brain-Boy Universal Professional we wstępnej ocenie zaburzeń przetwarzania słuchowego]. Pol Merkur Lekarski. 2017;43(255):120-4.

21. Shaikh MA, Baker B, Levya A. Comparison of Questionnaire-Based and Performance-Based Screening Tools as Predictors of Auditory Processing Disorder...American Speech-Language-Hearing Association's Convention 2018, November 15-17, Boston, MA. Am J Audiol. 2020;29(2):143-51. D0l:10.1044/2019_AJA-19-00025.

22. Skarzynski PH, Wlodarczyk AW, Kochanek K, Pilka A, Jedrzejczak WW, Olszewski L, et al. Central auditory processing disorder (CAPD) tests in a school-age hearing screening programme - analysis of 76,429 children. Ann Agric Environ Med. 2015;22(1):90-5. D0l:10.5604/12321966.1141375.

23. Sofokleous V, Marmara M, Panagiotopoulos GK, Mouza S, Tsofidou M, Sereti A, et al. Test-retest reliability of the Greek Speech-in-babble test (SinB) as a potential screening tool for auditory processing disorder. Int J Pediatr Otorhinolaryngol. 2020 Apr;131:109848. DOl:10.1016/j.jporl.2019.109848

24. Strange AK, Zalewski TR, Waibel-Duncan MK. Exploring the usefulness of Fisher's Auditory Problems Checklist as a screening tool in relationship to the Buffalo Model Diagnostic Central Auditory Processing Test Battery. J Educ Audiol. 2009;15:44-52.

25. Vaidyanath R, Yathiraj A. Screening checklist for auditory processing in adults (SCAP-A): Development and preliminary findings. J Hear Sci. 2014;4(1):27-37.

26. Wilson WJ, Jackson A, Pender A, Rose C, Wilson J, Heine C, et al. The CHAPS, SIFTER, and TAPS-R as predictors of (C)AP skills and (C)APD. J Speech Lang Hear Res. 2011;54(1):278-91.

27. Yathiraj A, Maggu AR. Comparison of a screening test and screening checklist for auditory processing disorders. Int J Pediatr Otorhinolaryngol. 2013;77(6):990-5. DOI:10.1016/j.ijporl.2013.03.028.

28. Yathiraj A, Maggu AR. Screening Test for Auditory Processing (STAP): a preliminary report. J Am Acad Audiol. 2013;24(9):867-78. D0I: 10.3766/jaaa.24.9.10. 